\title{
Circumstances and Witness Characteristics Associated With Overdose Fatality
}

Amy S. B. Bohnert, PhD

Melissa Tracy, MPH

Sandro Galea, MD, DrPH
From the VA National Serious Mental IIIness Treatment Research and Evaluation Center, Ann Arbor, MI (Bohnert); the Department of Psychiatry (Bohnert) and the Survey Research Center, Institute for Social Research, the Department of Epidemiology, University of Michigan School of Public Health, Ann Arbor, MI (Tracy, Galea); and the Department of Emergency Medicine (Galea), University of Michigan, Ann Arbor, MI.

Study objective: Emergency physicians have an opportunity to provide overdose fatality prevention interventions to individuals at risk for experiencing or witnessing an overdose to reduce fatality. The present study uses data about the most recent overdose observed by a sample of inner-city drug users to determine the circumstances of overdose that are associated with overdose fatality.

Methods: Participants $(n=690)$ aged 18 years or older were recruited with targeted street outreach. All participants had used heroin or cocaine in the previous 2 months and had witnessed at least 1 overdose. Survey data included the circumstances of the last overdose witnessed, including actions taken, drug use behavior, the location of the event, and whether or not the overdose was fatal (the outcome measure).

Results: One hundred fifty-two $(21.7 \%)$ of the witnessed overdoses were fatal. Witness powdered cocaine use (adjusted odds ratio=1.6; 95\% confidence interval $[\mathrm{Cl}] 1.0$ to 2.6) and injection drug history (adjusted odds ratio $=0.5 ; 95 \% \mathrm{Cl} 0.3$ to 0.9 ) were associated with the last witnessed overdose being fatal. Witnessed overdoses that occurred in public or abandoned buildings compared with homes were more likely to be fatal (adjusted odds ratio $=1.9 ; 95 \% \mathrm{Cl} 1.0$ to 3.5 ), as were overdoses in which witnesses sought outside medical help (adjusted odds ratio $=1.5 ; 95 \% \mathrm{Cl} 1.0$ to 2.1 ).

Conclusion: Future prevention interventions may fruitfully target users of powdered cocaine, drug users without a history of injecting, and individuals who use drugs in public or abandoned buildings for brief interventions on responding when witnessing an overdose to reduce mortality. [Ann Emerg Med. 2009;54:618-624.]

Provide feedback on this article at the journal's Web site, www.annemergmed.com.

0196-0644/\$-see front matter

Copyright (C) 2009 by the American College of Emergency Physicians.

doi:10.1016/j.annemergmed.2009.05.004

\section{INTRODUCTION \\ Background}

Accidental overdose is second only to motor vehicle crashes as a leading cause of accidental death in the United States among adults, and more than 700,000 emergency department $(\mathrm{ED})$ visits in 2006 were attributed to accidental overdoses. ${ }^{1}$ Among drug users, drug overdose is a leading cause of mortality. ${ }^{2}$ Although the health consequences of nonfatal overdoses are considerable, ${ }^{3}$ fatality caused by overdose presents a crucial target for prevention efforts.

Zinberg ${ }^{4}$ identified 3 categories of factors that are associated with the effect of a drug and consequently the risk of overdose and overdose fatality. First are the characteristics of the drug(s) used, such as purity ${ }^{5}$ or particular combination of drugs. ${ }^{6,7}$ The second category is the characteristics of the drug user, eg, physiologic attributes such as a lowered tolerance after a period of abstinence. ${ }^{8}$ Finally, the third category is characteristics of the setting in which the drug use occurs, such as the type of location in which the overdose occurs. ${ }^{9}$ The first category of factors associated with overdose and overdose fatality, characteristics of the drug itself, have been studied extensively with medical examiner reports, death records, and data from ED settings. ${ }^{6,9-14}$ In these studies, toxicology reports provide much of the information available about the circumstances surrounding the overdose. Consequently, less is known about settings associated with overdose and overdose fatality. We sought to extend previous research on overdose fatality by examining how characteristics of the setting in which the overdose occurred are associated with whether or not the overdose is fatal.

\section{Importance}

Because many individuals who use drugs do so with others, overdose often occurs in the presence of witnesses. ${ }^{12,15}$ The actions taken by the witnesses may be important determinants of whether the overdose victim survives. Previous research has found that witnesses of an overdose often do take action to prevent fatality, ${ }^{16-18}$ but there has been limited research that has 


\section{Editor's Capsule Summary}

What is already known about this topic

Little is known about the epidemiology of fatal illicit drug overdoses.

\section{What question this study addressed}

What are the circumstances and settings associated with increased risk of unintentional fatality from illicit drug use?

\section{What this study adds to our knowledge}

The majority (67\%) of subjects in this crosssectional survey of 1,184 inner-city illicit drug users had witnessed an unintentional overdose, $23 \%$ of which were fatal. Witnessed deaths were more likely to occur in public or abandoned buildings.

\section{How this might change clinical practice}

These findings will not change practice but can inform interventions designed to decrease illicit drug use and unintentional overdose.

explored how the characteristics and actions of these witnesses relate to overdose fatality.

Individuals who have experienced a nonfatal overdose are more likely to witness drug overdoses, ${ }^{18}$ and drug users often have contact with medical providers. Consequently, the contact emergency medical professionals have with drug users provides an opportunity to communicate messages on appropriate responses when an overdose is witnessed to reduce fatality.

\section{Goals of This Investigation}

We used data that includes information on the situation surrounding the overdose in connection to the main outcome of fatality to identify circumstances of overdoses most likely to result in death. Specifically, we included information on the characteristics of the overdose witness, whether witnesses sought medical help, and the location of the overdose in a multivariable logistic model of overdose fatality. Identifying circumstances related to overdose fatality can inform the development of targeted interventions to prevent fatality once an overdose has occurred.

\section{MATERIALS AND METHODS \\ Study Design}

The present study used cross-sectional observational data of a sample of current heroin or cocaine users in the Central Harlem and the South Bronx neighborhoods of New York City. The New York Academy of Medicine Institutional Review Board approved the study protocol, and all participants gave oral consent at the interview.

\section{Setting}

In New York City, drug overdose is a significant problem; in 2007 death caused by drug use and accidental overdose was the third leading cause of death among residents aged 15 to 34 years and fourth leading cause of death among residents aged 35 to 54 years. ${ }^{19}$ The drugs most commonly responsible for overdose deaths in New York City are cocaine and heroin, often in combination with alcohol. ${ }^{6}$ Among black men in New York City, the most common cause of overdose deaths is cocaine alone, whereas cocaine and opiates together were the most common cause among white and Latino men. ${ }^{6}$ The rate of drug-related hospitalizations and deaths in the neighborhoods in the recruitment area are historically higher than for New York City as a whole ${ }^{20-23}$ with roughly 1,200 to 2,400 or more drugrelated hospitalizations per 100,000 residents per year for these neighborhoods compared with a New York City-wide average of approximately 600 .

\section{Selection of Participants}

Trained outreach workers (who were residents of the same communities as participants) recruited participants using targeted sampling with street outreach techniques ${ }^{24-26}$ from November 2001 to February 2004. Recruiters approached individuals in public areas in the target neighborhoods that were identified by ethnographic research as areas where drug users congregated. Recruiters engaged potential participants in conversation, assessed eligibility through structured questions, and escorted eligible and interested individuals to the study office located in the neighborhood. To participate, respondents were required to be 18 years of age or older and to have used heroin or cocaine through any route of administration in the 2 months before the interview. The present report includes only those participants who reported having ever witnessed an overdose.

\section{Data Collection and Processing}

Data collection for the study has been described in detail elsewhere. ${ }^{18,27,28}$ In-person interviews were conducted in English or Spanish by trained interviewers. Identifying data were kept in separate files from responses to the study questionnaire. Participant responses were protected by a federal certificate of confidentiality, and all interviews took place in private and behind a closed door, either in a study research storefront or a study-owned mobile van. All study records were double entered and stored on password-protected computers with data encrypted, and hard copies of data were destroyed at the end of the study. Respondents received a nominal incentive to participate in the parent study. All participants were offered referrals to substance use treatment as appropriate, and clinical staff affiliated with the study facilitated referral for participants who wished to pursue referral.

\section{Methods of Measurement}

Domains covered in the questionnaire included demographic characteristics, drug use behavior, overdose experiences, and 
experiences witnessing the overdose of others. For the purposes of the study, "overdose" was defined as someone who collapses, has blue skin, has convulsions, has difficulty breathing, loses consciousness, cannot be woken up, or has a heart attack or dies while using drugs. ${ }^{29,30}$ Participants were asked the location of the most recent overdose that they witnessed, with the choices of a private residence (including their own or someone else's), a shooting gallery (according to the respondent's knowledge that it is a location injection drug users use), an open public space (such as a street, schoolyard, or parking lot), a public or abandoned building (including bars, stores, and hotel rooms), or other. Interviewers asked participants how many overdoses they had ever witnessed, whether they had ever known someone who died of an overdose, and how many overdoses they had heard about in the past year. Interviewers additionally asked those participants who reported having witnessed at least 1 overdose questions about the last overdose they witnessed, including the recency, what drugs the overdose victim was using at the time, what actions were taken by the respondent and other witnesses, and whether the overdose victim lived or died. Seeking medical assistance for the overdose victim was defined as witnesses calling an ambulance or taking the overdose victim to the hospital.

\section{Primary Data Analysis}

The primary analytic goal of the study was to create a multivariable logistic regression model with the outcome of fatality for the most recent witnessed overdose for all participants who reported witnessing at least 1 overdose. We selected covariates for modeling according to theoretic plausibility and previous empirical findings. We hypothesized that getting help for the overdose victim would be associated with fatality, according to the findings of Davidson et al. ${ }^{9}$ Tracy et $\mathrm{al}^{18}$ found that overdose location was associated with witnesses calling for help, and Davidson et $\mathrm{al}^{17}$ found that witness race was related to getting help for an overdose victim. We hypothesized that those witnesses who sought outside help would also be more likely to intervene in other ways that would reduce the risk of fatality for an overdose victim. Consequently, we hypothesized that location and witness race may have an association with overdose fatality beyond that which is explained through witnesses seeking outside help. Because existing prevention efforts targeting actions taken by overdose witnesses have been administered through needle exchange programs or have targeted heroin users, ${ }^{31,32}$ we included witness drug use type and injection history. Because it has been suggested that drug users at older ages may engage in drug use patterns that impart more risk for overdose, ${ }^{13}$ and age may be associated with types of drug used (because of the relative popularity of drugs by age cohort) and drug use location, we included witness age as a potentially important control variable. In total, these variables use $14 d f$.

To create a more parsimonious model, we removed variables that did not have a relationship with fatality after adjustment for other covariates $(P>.05)$. After each removal of data from the multivariable model, we considered whether the variable was an important confounder according to the effect its removal had on the other covariates in the model and retained the variable if this was found to be the case. ${ }^{33} \mathrm{~A}$ variable was considered a potentially important confounder if its removal resulted in changes greater than $10 \%$ in the estimates $(\beta)$ for retained variables. We also tested an interaction between overdose location and getting medical attention. We conducted all analyses with Stata 9 (StataCorp, College Station, TX).

\section{RESULTS}

Study staff approached 1,228 participants who met initial eligibility criteria and gave informed consent; 44 were later determined to not be eligible. Of the 1,184 respondents who completed the survey, 797 (67.3\%) reported having witnessed at least 1 overdose. Among those who had witnessed an overdose, $554(71.0 \%)$ knew at least 1 person who died of an overdose, and $523(67.1 \%)$ reported hearing about an overdose in the past year, with the mean number of overdoses heard about being $4.7(\mathrm{SD}=7.5)$. Of those who reported ever witnessing an overdose, $35.2 \%$ reported witnessing an overdose in the previous 6 months; the mean number witnessed during the lifetime was $11.8(\mathrm{SD}=20.9)$, and the median number of witnessed overdoses was 5 .

The outcome (fatal or not fatal) was known for 721 of the 797 (90.5\%) last overdoses witnessed. Of the 721 overdoses with a known outcome, $163(22.5 \%)$ were fatal. The majority of witnesses who knew the outcome of the last overdose they witnessed were Hispanic $(n=433 ; 60.1 \%)$, men $(n=534$; $74.5 \%)$, never married ( $\mathrm{n}=444 ; 61.6 \%)$, had ever injected drugs $(n=611 ; 85.9 \%)$, had used heroin in the past year $(\mathrm{n}=644 ; 89.3 \%)$, had ever experienced homelessness $(\mathrm{n}=632$; $87.8 \%)$, and were between the ages of 25 and 44 years $(n=510$; $70.7 \%)$. The victim used heroin $(n=613 ; 89.1 \%)$ and injected drugs $(n=632 ; 90.4 \%)$ in the majority of the most recent witnessed overdoses with a known outcome reported.

Witnesses called for an ambulance or took the victim to the hospital for 313 (44.0\%) of all witnessed overdoses with a known outcome reported. Among the 399 witnessed overdoses in which medical attention was not sought, 75 (18.8\%) resulted in fatality. Among those overdose victims for whom witnesses did seek outside help, 83 (26.5\%) died as a result of the overdose.

For the 721 witnesses who knew the fatality outcome of the last overdose he or she witnessed, 31 (4.3\%) were not able to be included in modeling because of missing data. Table 1 reports the sample description for the analytic sample (ie, the 690 individuals without missing data). Observations not included were not different from those included in terms of age group, history of injection drug use, location of witnessed overdose, witness use of crack cocaine or powdered cocaine, or likelihood of seeking outside help for the overdose victim. Those witnesses with missing data were more likely to be black (50.0 versus $\left.24.9 \% ; \chi^{2}(1)=9.40 ; P=.002\right)$ but not Hispanic (36.7 versus $\left.61.2 \% ; \chi^{2}(1)=7.19 ; P=.007\right)$ and were less likely to have used 
Table 1. Witness and overdose characteristics by fatality of the last witnessed overdoses.

\begin{tabular}{|c|c|c|c|}
\hline \multirow[b]{2}{*}{ Variable } & \multicolumn{3}{|c|}{ Last Witnessed Overdose } \\
\hline & $\begin{array}{c}\text { Sample } \\
(\mathrm{n}=690) \\
\%\end{array}$ & $\begin{array}{c}\begin{array}{c}\text { Fatal } \\
(\mathrm{n}=152) \\
\%\end{array}\end{array}$ & $\begin{array}{c}\text { Nonfatal } \\
(n=538), \\
\%\end{array}$ \\
\hline \multicolumn{4}{|l|}{ Witness characteristics } \\
\hline \multicolumn{4}{|l|}{ Race } \\
\hline Hispanic & 61.2 & 54.0 & 63.2 \\
\hline Black & 24.9 & 29.6 & 23.6 \\
\hline White/other & 13.9 & 16.5 & 13.2 \\
\hline Female sex & 24.6 & 25.7 & 24.3 \\
\hline High school education & 51.0 & 53.0 & 50.4 \\
\hline \multicolumn{4}{|l|}{ Age, y } \\
\hline $18-24$ & 7.0 & 5.9 & 7.3 \\
\hline $25-34$ & 30.3 & 24.3 & 32.0 \\
\hline $35-44$ & 41.0 & 46.7 & 39.4 \\
\hline$\geq 45$ & 21.7 & 23.1 & 21.3 \\
\hline \multicolumn{4}{|l|}{ Drug use, past year } \\
\hline Heroin & 90.6 & 88.2 & 91.3 \\
\hline Crack cocaine & 63.0 & 69.1 & 61.3 \\
\hline Powdered cocaine & 75.8 & 80.3 & 74.5 \\
\hline Injected drugs (ever) & 86.2 & 79.0 & 88.3 \\
\hline \multicolumn{4}{|l|}{$\begin{array}{l}\text { Circumstances of } \\
\text { overdose }\end{array}$} \\
\hline \multicolumn{4}{|l|}{ Location } \\
\hline Private residence & 37.5 & 33.6 & 38.7 \\
\hline Shooting gallery & 17.3 & 14.5 & 18.0 \\
\hline Open public area & 21.7 & 21.1 & 21.9 \\
\hline $\begin{array}{l}\text { Public or abandoned } \\
\text { building }\end{array}$ & 10.4 & 13.8 & 9.5 \\
\hline Other & 13.0 & 17.1 & 11.9 \\
\hline $\begin{array}{l}\text { Witnesses called an } \\
\text { ambulance or took } \\
\text { to hospital }\end{array}$ & 43.5 & 51.3 & 41.3 \\
\hline
\end{tabular}

heroin in the past year $\left(61.3\right.$ versus $90.6 \% ; \chi^{2}(1)=26.7$; $P<.001)$.

As shown in model 1 in Table 2, the witness not having a history of injection drug use and seeking medical attention for the victim, as well as the overdose taking place in a public or abandoned building compared with a private home, was significantly associated (the 95\% confidence interval [CI] did not include 1.00) with a higher likelihood of the witnessed overdose being fatal. We created a second multivariable logistic model by removing variables that were not significant $(95 \% \mathrm{CI}$ included 1.00) one at a time, considering their potential role as an important confounder for other covariates. Witness race/ ethnicity, crack cocaine use, and heroin use did not act as confounders of the relations of other covariates with the outcome because the changes in estimates $(\beta)$ for retained variables before and after the removal of these variables were less than $10 \%$. Consequently, we did not retain these variables in model 2. When age was removed from the model, the value of the estimates for injection drug use history and the overdose occurring in a public or abandoned building changed by $16 \%$ and $11 \%$, respectively; consequently, we retained age as a control variable. There was no significant interaction between overdose location in a public or abandoned building and getting medical attention. For model 2 shown in Table 2, the witness being a user of powdered cocaine, the witness not having a history of injection drug use, the overdose taking place in a public or abandoned building compared with a private home, and witnesses seeking medical attention were associated with a higher likelihood of the witnessed overdose being fatal, as indicated by $95 \%$ CIs that did not include 1.00 . Both the full model and the parsimonious model had acceptable local and global fit, as indicated by the Hosmer-Lemeshow and likelihood ratio tests.

\section{LIMITATIONS}

There are several limitations to the present study. We used retrospective cross-sectional data, which are subject to errors and biases in recall. Given the recruitment methods, the sample may not be representative of all drug users in terms of their experiences with witnessing overdoses. Specifically, because the sample was composed of chronic drug users, the frequency of witnessing overdoses may be overestimated. Recruitment methods do not allow for a count of persons who did not wish to participate. Although these methods are standard in studies that aim to recruit high-risk participants, ${ }^{18,28,34,35}$ we were unable to calculate the percentage of eligible participants who consented and completed the survey. Furthermore, this study was conducted in a large city on the east coast of the United States. Characteristics associated with witnessing a fatal overdose may be quite different in other parts of the country, particularly rural areas and regions with different trends in drug use. Additionally, the effect sizes found in multivariable modeling were relatively small (odds ratios ranging between 0.54 and 1.90). Previous evidence suggests that many fatal overdoses occur when the overdose victim is alone ${ }^{9}$ and no witnesses are present to act; however, overdoses that were not witnessed were outside the scope of this study, and the percentage of overdoses that were fatal may underrepresent the true proportion.

Despite these limitations, the present study extended previous knowledge of factors associated with overdose fatality by using data collected from witnesses of overdoses, rather than hospital or death records. We found that $56 \%$ of overdose witnesses reported that they did not seek medical attention for the victim, consistent with other studies that have found that medical care is sought for roughly half of overdose victims. ${ }^{16,17}$ Findings from studies using hospital records may be subject to selection biases according to differences in which witnesses are more likely to seek medical treatment for the victim.

\section{DISCUSSION}

In a study of urban chronic heroin or cocaine users, we found that $67.3 \%$ had witnessed at least 1 overdose. Among those who had witnessed an overdose, $22.5 \%$ of the most recent witnessed overdoses were fatal. We found that characteristics of both the witness and the situation in which an overdose takes place are associated with whether or not the overdose is fatal. 
Table 2. Multivariable models of overdose fatality among last witnessed overdose $(n=690)$.

\begin{tabular}{|c|c|c|c|c|}
\hline \multirow[b]{2}{*}{ Variable } & \multicolumn{2}{|c|}{ Model 1* } & \multicolumn{2}{|c|}{ Model $2^{\dagger}$} \\
\hline & Adjusted Odds Ratio & 95\% Cl & Adjusted Odds Ratio & $95 \% \mathrm{Cl}$ \\
\hline \multicolumn{5}{|l|}{ Witness characteristics } \\
\hline \multicolumn{5}{|l|}{ Race } \\
\hline Hispanic & 1.00 & - & & \\
\hline Black & 1.16 & $0.71-1.90$ & & \\
\hline White/other & 1.45 & $0.84-2.47$ & & \\
\hline \multicolumn{5}{|l|}{ Age, y } \\
\hline $18-24$ & 0.71 & $0.31-1.60$ & 0.69 & $0.31-1.54$ \\
\hline 25-34 & 0.64 & $0.40-1.04$ & 0.66 & $0.41-1.05$ \\
\hline 35-44 & 1.00 & - & 1.00 & - \\
\hline $45-54$ & 0.91 & $0.56-1.48$ & 0.92 & $0.57-1.49$ \\
\hline \multicolumn{5}{|l|}{ Drug use, past year } \\
\hline Crack cocaine & 1.25 & $0.83-1.88$ & & \\
\hline Powdered cocaine & 1.57 & $0.98-2.51$ & 1.64 & $1.03-2.60$ \\
\hline Heroin & 1.04 & $0.54-2.02$ & & \\
\hline Injected drugs (ever) & 0.55 & $0.32-0.97$ & 0.54 & $0.32-0.90$ \\
\hline \multicolumn{5}{|l|}{ Circumstances of overdose } \\
\hline \multicolumn{5}{|l|}{ Location } \\
\hline Private residence & 1.00 & - & 1.00 & - \\
\hline Shooting gallery & 1.17 & $0.65-2.11$ & 1.08 & $0.61-1.92$ \\
\hline Open public area & 1.19 & $0.71-1.99$ & 1.13 & $0.68-1.88$ \\
\hline Public or abandoned building & 1.95 & $1.06-3.60$ & 1.90 & $1.03-3.49$ \\
\hline Other & 1.74 & $0.98-3.09$ & 1.71 & $0.97-3.02$ \\
\hline $\begin{array}{l}\text { Witnesses called an ambulance } \\
\text { or took to hospital }\end{array}$ & 1.46 & $1.00-2.25$ & 1.46 & $1.01-2.13$ \\
\hline \multicolumn{5}{|l|}{ Model diagnostics } \\
\hline Likelihood ratio & \multicolumn{2}{|c|}{$\chi^{2}(14)=28.40 ; P=.013$} & \multicolumn{2}{|c|}{$\chi^{2}(10)=24.98 ; P=.005$} \\
\hline Hosmer-Lemeshow & \multicolumn{2}{|c|}{$\chi^{2}(8)=4.29 ; P=.83$} & \multicolumn{2}{|c|}{$\chi^{2}(8)=7.51 ; P=.48$} \\
\hline
\end{tabular}

Those witnesses who use powdered cocaine were more likely to report that the last overdose they observed was fatal than were witnesses who do not use powdered cocaine, controlling for their history of injection drug use. In contrast, those witnesses with a history of injection drug use were only about half as likely to report that the last overdose they observed was fatal compared with witnesses without a history of injection drug use. In regard to the location of the overdose, we found that overdoses in public or abandoned buildings were almost twice as likely to be fatal than overdoses in a private home. Overdose situations in which the witnesses called an ambulance or took the overdose victim to the hospital were also more likely to be fatal.

Although more than $90 \%$ of the sample reported recent heroin use, other aspects of the drug use history of the witness were associated with overdose fatality. Injection drug users were less likely to report the last witnessed overdose as fatal, whereas powdered cocaine users were more likely to report the last witnessed overdose as fatal. Needle exchange programs are increasingly providing overdose prevention programs. ${ }^{31}$ Additionally, in a large community sample of drug users, those who had injected drugs reported greater willingness to treat someone whom they witnessed overdosing. ${ }^{36}$ Our findings suggest that injection drug users may have greater knowledge of how to react to an overdose because of contact with needle exchange programs and more experiences with overdose compared with those who have not injected drugs and that this may result in a lower risk of fatality for an overdose when an injection drug user is present.

Previous literature has shown that overdoses in which witnesses sought emergency medical services were more likely to result in a fatality. ${ }^{17}$ This is consistent with our finding that witnesses taking the overdose victim to the hospital or calling for an ambulance was associated with a greater likelihood of the overdose being fatal, likely reflecting that witnesses seek medical attention when an overdose is more severe and the victim could not be revived.

The setting of the overdose was also an important correlate of fatality. One possible explanation for the finding that overdoses that occur in a public or abandoned building are more likely to be fatal than those in a private residence is that those witnesses in a public or abandoned building felt less responsible to take action than they would if the overdose occurred in their own or a friend's home. However, the location of the overdose was still associated with fatality in multivariable models that included seeking medical help, and we found no 
evidence for an interaction between the location of the overdose and seeking medical attention.

This study has important implications for intervention. Several studies have demonstrated the feasibility and effectiveness of network-based overdose prevention programs. ${ }^{32,37-39}$ These studies have focused primarily on heroin overdose, in large part because of the availability of naloxone as an effective antidote that can be administered by trained laypersons. Our findings suggest that individuals who use powdered cocaine (and who may or may not use heroin) are less equipped to intervene when they are witnessing an overdose. Surveillance for the National Vital Statistics Reports suggests that the number of overdose deaths (regardless of intent) in which cocaine is mentioned in the death certificates has increased by $62.5 \%$ between 1999 and 2005, whereas heroin has increased in mentions by only $2.4 \% .{ }^{40}$ Furthermore, cocaine was the most commonly mentioned narcotic during that period. ${ }^{40}$ Future efforts at developing interventions to reduce fatality among overdose victims by educating drug users on actions to take in the event of overdose should adapt proven interventions and target cocaine users and other noninjection drug users. Given the findings of the present study, such interventions should also target drug users who frequently use drugs in public or abandoned buildings.

Emergency physicians are well positioned to provide brief interventions to drug users seeking care for nonoverdose and overdose-related emergencies. Those witnesses who bring an overdose victim to the ED may also be fruitfully involved in intervention. According to proven interventions for overdose harm reduction, ${ }^{32,39}$ the intervention could take the form of an educational session on how to quickly recognize an overdose and on providing first aid in the event of witnessing an overdose. Findings from the present study indicate characteristics of drug users who may be more likely to have been missed by existing, community-based harm reduction efforts to prevent overdose fatality in urban settings and who may be well served by overdose-related education beyond that which is provided during usual care in EDs.

Witnessing an overdose is a common experience among chronic drug users in inner-city locations, and witnesses play an important role in determining whether an overdose is fatal. Study findings suggest that drug users in urban locations who use powdered cocaine are less prepared to respond when they witness an overdose compared with drug users who do not use powdered cocaine, controlling for history of injection drug use. Overdoses that occur in public or abandoned buildings were also more likely to result in fatality than overdoses in a private home. Future prevention interventions should educate urban drug users who use powdered cocaine and use drugs in public or abandoned buildings to take action to reduce the risk of fatality when witnessing an overdose. Emergency physicians, when involved in the treatment of drug users in urban locations, have the opportunity to target individuals with these characteristics, who may be missed by other community-based interventions, for overdose fatality prevention education.

The authors wish to acknowledge the work of Philip O. Coffin, MD, Crystal Fuller, PhD, Danielle Ompad, PhD, and David Vlahov, PhD, in study setup.

Supervising editor: E. Martin Caravati, MD, MPH

Author contributions: ASBB conducted data analysis and took primary responsibility for the writing of the article. MT assisted in data analysis. MT and SG contributed toward the writing of the article. SG obtained funding for the data collection. ASBB, $\mathrm{MT}$, and SG contributed to the conceptualization of the analysis described in the article. ASBB takes responsibility for the paper as a whole

Funding and support: By Annals policy, all authors are required to disclose any and all commercial, financial, and other relationships in any way related to the subject of this article that might create any potential conflict of interest. See the Manuscript Submission Agreement in this issue for examples of specific conflicts covered by this statement. This study was funded by grants MH-053399, DA-06534, DA-12801-S1, and DA-017642 from the National Institutes of Health.

Publication dates: Received for publication March 24, 2009. Revision received April 22, 2009. Accepted for publication May 5, 2009. Available online June 21, 2009.

Reprints not available from the authors.

Address for correspondence: Amy S. B. Bohnert, PhD, VA Ann Arbor SMITREC (11H), 2215 Fuller Rd, Ann Arbor, MI 48105; 734-232-0185, fax 734-845-3249; E-mail amybohne@med.umich.edu.

\section{REFERENCES}

1. Centers for Disease Control and Prevention, National Center for Injury Prevention and Control. Web-based Injury Statistics Query and Reporting System (WISQARS). 2008. (Cited March 18, 2009.) Available at: http://www.cdc.gov/ncipc/wisqars.

2. Bargagli AM, Sperati A, Davoli M, et al. Mortality among problem drug users in Rome: an 18-year follow-up study, 1980-97. Addiction. 2001;96:1455-1463.

3. Warner-Smith M, Darke S, Day C. Morbidity associated with nonfatal heroin overdose. Addiction. 2002;97:963-967.

4. Zinberg NE. Drug, Set, and Setting. New Haven, CT: Yale University Press; 1984.

5. Darke S, Hall W, Weatherburn D, et al. Fluctuations in heroin purity and the incidence of fatal heroin overdose. Drug Alcohol Depend. 1999;54:155-161.

6. Coffin PO, Galea S, Ahern J, et al. Opiates, cocaine and alcohol combinations in accidental drug overdose deaths in New York City, 1990-98. Addiction. 2003;98:739-747.

7. Darke S, Ross J, Hall W. Overdose among heroin users in Sydney, Australia, I: prevalence and correlates of non-fatal overdose. Addiction. 1996;91:405-411.

8. Warner-Smith M, Darke S, Lynskey M, et al. Heroin overdose: causes and consequences. Addiction. 2001;96:1113-1125.

9. Davidson PJ, McLean RL, Kral AH, et al. Fatal heroin-related overdose in San Francisco, 1997-2000: a case for targeted intervention. J Urban Health. 2003;80:261-273. 
10. Webb L, Oyefeso A, Schifano F, et al. Cause and manner of death in drug-related fatality: an analysis of drug-related deaths recorded by coroners in England and Wales in 2000. Drug Alcohol Depend. 2003;72:67-74.

11. Darke S, Ross J. Fatal heroin overdoses resulting from noninjecting routes of administration, NSW, Australia, 1992-1996. Addiction. 2000;95:569-573.

12. Zador D, Sunjic S, Darke S. Heroin-related deaths in New South Wales, 1992: toxicological findings and circumstances. Med J Aust. 1996;164:204-207.

13. Hall W, Darke S. Trends in opiate overdose deaths in Australia 1979-1995. Drug Alcohol Depend. 1998;52:71-77.

14. Bernstein KT, Bucciarelli A, Piper TM, et al. Cocaine- and opiaterelated fatal overdose in New York City, 1990-2000. BMC Public Health. 2007;7:31.

15. Powis B, Strang J, Griffiths P, et al. Self-reported overdose among injecting drug users in London: extent and nature of the problem. Addiction. 1999;94:471-478.

16. Darke S, Ross J, Hall W. Overdose among heroin users in Sydney, Australia, II: responses to overdose. Addiction. 1996;91: 413-417.

17. Davidson PJ, Ochoa KC, Hahn JA, et al. Witnessing heroin-related overdoses: the experiences of young injectors in San Francisco. Addiction. 2002;97:1511-1516.

18. Tracy M, Piper TM, Ompad D, et al. Circumstances of witnessed drug overdose in New York City: implications for intervention. Drug Alcohol Depend. 2005;79:181-190.

19. Bureau of Vital Statistics. Summary of vital statistics 2007: the City of New York: New York City Department of Health and Mental Hygiene. 2008. (Cited April 22, 2009.) Available at: http://www.nyc.gov/html/doh/downloads/pdf/vs/2007sum.pdf.

20. New York City Department of Health and Mental Hygiene. Community health: Central Harlem. 2006. (Cited April 22, 2009.) Available at: http://www.nyc.gov/html/doh/downloads/pdf/data/ 2006chp-302.pdf.

21. New York City Department of Health and Mental Hygiene. Community health: East Harlem. 2006. (Cited April 22, 2009.) Available at: http://www.nyc.gov/html/doh/downloads/pdf/data/ 2006chp-303.pdf.

22. New York City Department of Health and Mental Hygiene. Community health: Highbridge and Morrisania, the Bronx. 2006. (Cited April 22, 2009.) Available at: http://www.nyc.gov/html/ doh/downloads/pdf/data/2006chp-106.pdf.

23. New York City Department of Health and Mental Hygiene. Community health: Hunts Point and Mott Haven, the Bronx. 2006. (Cited April 22, 2009.) Available at: http://www.nyc.gov/ $\mathrm{html} /$ doh/downloads/pdf/data/2006chp-107.pdf.

24. Diaz T, Des Jarlais DC, Vlahov D, et al. Factors associated with prevalent hepatitis $\mathrm{C}$ : differences among young adult injection drug users in lower and upper Manhattan, New York City. Am J Public Health. 2001;91:23-30.
25. Diaz T, Vlahov D, Greenberg B, et al. Sexual orientation and HIV infection prevalence among young Latino injection drug users in Harlem. J Womens Health Gend Based Med. 2001;10:371-380.

26. Ompad DC, Galea S, Fuller CM, et al. Ecstasy use among Hispanic and black substance users in New York City. Subst Use Misuse. 2005;40:1399-1407.

27. Coffin PO, Tracy M, Bucciarelli A, et al. Identifying injection drug users at risk of nonfatal overdose. Acad Emerg Med. 2007;14: 616-623.

28. Galea S, Nandi A, Coffin PO, et al. Heroin and cocaine dependence and the risk of accidental non-fatal drug overdose. $J$ Addict Dis. 2006;25:79-87.

29. McGregor C, Darke S, Ali R, et al. Experience of non-fatal overdose among heroin users in Adelaide, Australia: circumstances and risk perceptions. Addiction. 1998;93:701-711.

30. Ochoa KC, Hahn JA, Seal KH, et al. Overdosing among young injection drug users in San Francisco. Addict Behav. 2001;26: 453-460.

31. Huriaux E. More than clean needles: overdose prevention and syringe exchange. Focus. 2007;22:5-6.

32. Markham Piper T, Stancliff S, Rudenstine S, et al. Evaluation of a naloxone distribution and administration program in New York City. Substance Use Misuse. 2008;43:858-870.

33. Vittinghoff E, Glidden DV, Shiboski SC, et al. Predictor selection. In: Regression Methods in Biostatistics: Linear, Logistic, Survival, and Repeated Measures Models. New York, NY: Springer; 2005: 133-156.

34. Novoa RA, Ompad DC, Wu Y, et al. Ecstasy use and its association with sexual behaviors among drug users in New York City. J Community Health. 2005;30:331-343.

35. Ompad DC, Galea S, Marshall G, et al. Sampling and recruitment in multilevel studies among marginalized urban populations: the IMPACT studies. J Urban Health. 2008;85:268-280.

36. Lagu T, Anderson BJ, Stein M. Overdoses among friends: drug users are willing to administer naloxone to others. J Subst Abuse Treat. 2006;30:129-133.

37. Seal KH, Thawley R, Gee L, et al. Naloxone distribution and cardiopulmonary resuscitation training for injection drug users to prevent heroin overdose death: a pilot intervention study. $J$ Urban Health. 2005;82:303-311.

38. Strang J, Manning V, Mayet S, et al. Overdose training and takehome naloxone for opiate users: prospective cohort study of impact on knowledge and attitudes and subsequent management of overdoses. Addiction. 2008;103:1648-1657.

39. Tobin KE, Sherman SG, Beilenson P, et al. Evaluation of the Staying Alive programme: training injection drug users to properly administer naloxone and save lives. Int J Drug Policy. 2008;20: 131-136.

40. Fingerhut LA. Increases in poisoning and methadone-related deaths: United States, 1999-2005. Centers for Disease Control and Prevention; 2008. (Cited April 22, 2009.) Available at: http://www.cdc.gov/nchs/products/pubs/pubd/hestats/ poisoning/poisoning.htm. 